\title{
Visuospatial Reasoning and Its Relation to External Variables
}

\author{
Juliana Carnevalli Siqueira Nery \\ Universidade São Francisco, \\ Itatiba-SP, Brazil
}

\author{
Fabián Javier Marín Rueda ${ }^{1}$ \\ Universidade São Francisco, \\ Itatiba-SP, Brazil
}

\begin{abstract}
In this study, the relation of age and sex with visuospatial reasoning assessed by the Cube Test was investigated. In addition, a comparative study was conducted between this study sample and the normative group of the test with regard to visuospatial reasoning performance results. Six hundred and eighty-four students participated in this study, from the city of Belo Horizonte (State of Minas Gerais, Brazil), aged between 15 and 57 years old, both male and female. The results showed both age and sex differences, where younger students showed a significantly higher performance than older students and men showed significantly higher averages than women in every test comparison. In the study with the normative sample, men showed higher averages than women throughout every age group and in the overall result of both studies. The results obtained reflect those found in the literature and highlight the influence of age and sex on visuospatial reasoning.
\end{abstract}

Keywords: reasoning, intelligence, intelligence measures, sex, developmental age groups

\section{Raciocínio Visuoespacial e Sua Relação com Variáveis Externas}

Resumo: O presente estudo teve por objetivo verificar a relação das variáveis idade e sexo com a capacidade de raciocínio visuoespacial a partir do Teste dos Cubos. Além disso, foi realizado estudo comparativo entre a amostra deste estudo e o grupo normativo do teste com relação aos resultados no desempenho do raciocínio visuoespacial. Participaram 684 estudantes de Belo Horizonte (Minas Gerais, Brasil) entre 15 e 57 anos de idade e de ambos os sexos. Os resultados mostraram diferença em função da idade e sexo, sendo que os estudantes mais novos apresentaram desempenho significativamente superior aos de maior idade e os homens obtiveram médias significativamente maiores que as mulheres em todas as comparações realizadas. No estudo com amostra normativa, os homens obtiveram médias maiores que as mulheres em todas as faixas etárias e no resultado geral de ambos os estudos. Os resultados foram ao encontro dos achados na literatura, destacando a influência da idade e do sexo no raciocínio visuoespacial.

Palavras-chave: raciocínio, inteligência, medidas de inteligência, sexo, grupos etários

\section{Raciocinio Viso-Espacial y Su Relación con Variables Externas}

Resumen: El estudio investigó la relación existente entre las variables edad y sexo con el raciocinio viso-espacial evaluado mediante el Test de los Cubos. Además, se realizó un estudio comparativo entre la muestra de este trabajo y el grupo normativo de la prueba con relación a los resultados en el desempeño del raciocinio viso-espacial. Participaron 684 estudiantes de Belo Horizonte (Minas Gerais, Brasil) con edades entre 15 y 57 años y ambos sexos. Los resultados mostraron diferencia en función de la edad y del sexo, siendo que los estudiantes más jóvenes tuvieron un desempeño significativamente mayor que los de más edad. Con relación al sexo, los hombres obtuvieron promedios significativamente mayores que las mujeres en todas las comparaciones hechas. En el estudio con la muestra normativa, los hombres también obtuvieron promedios mayores a las mujeres en todos los grupos de edad y en el resultado general de ambos estudios. Los resultados son compatibles con la literatura, que destaca la influencia de la edad y del sexo en el raciocinio viso-espacial.

Palabras clave: raciocinio, inteligencia, medidas de inteligencia, sexo, grupos por edad

Intelligence is one of the most studied concepts in Psychology (Primi, 2002) and, since the first half of the 20th century, researchers have been trying to understand and define its components (Almeida, Guisande, Primi, \& Ferreira, 2008). The visuospatial ability, which allows one to mentally generate, retain, recall and change stimuli, changing visual images (Lohman, 1993; Prieto, 2008), is among the most studied abilities in the intelligence scope as, together with the verbal and reasoning abilities, it explains most of the variance

\footnotetext{
1 Correspondence address:

Fabián Javier Marín Rueda. Universidade São Francisco, Faculdade de Ciências Humanas. Rua Alexandre Rodrigues Barbosa, 45, Centro. CEP 13251-900. Itatiba-SP, Brazil. E-mail: marinfabian@yahoo.com.br
}

in the scores obtained in intelligence multifactorial battery tests (Adanez \& Velasco, 2002; Carroll, 1993). Although visual and spatial abilities are commonly associated when the matter is discussed, Farah (1988) points out their representations as being distinct. According to the author, visual images refer to representations of colors and forms, while spatial images involve dimensions of depth, distances and orientations.

In the scope of cognitive abilities, two discussions have been found relevant and will be highlighted in this study. One is about the evolution of abilities over the years throughout life, that is, increase, stability and decline (Colom, 2008), and the other verifies the existence of similarities and differences between the sexes and possible explanations for them (Halpern, 2000; Prieto, 2008). 
With regard to the evolution of the cognitive abilities, scholars on the subject agree with the idea that they follow the maturity development of human beings and develop with aging, diverging only in relation to different ages and phases of the maturity process. Mumaw, Pellegrino, Kail, and Carter (1984), based on tests conducted with different age groups, consider that, with the maturity and learning process, subjects acquire abilities to decode and compare images until they reach the apex of spatial aptitude development and, after this period, there is an increase in the mental rotation speed or coded information transformation, reducing the performance of older people in the task. Woodcock (1999) shows a curve graph of seven cognitive factors (from 5 to 90 years old) assessed by the Woodcock-Johnson PsychoEducational Battery tests. The visual processing factor curve $(\mathrm{Gv})$ reaches its maximum around 25 years old and then declines, concluding that young adults have better visuospatial reasoning performance than older subjects.

However, with regard to sex, authors such as Prieto (2008) state that the difference in magnitude between men and women varies according to the different factors that have been assessed. According to Prieto, differences favoring men are great when spatial relation or mental rotation tests are used. Male superiority is considered to be median when spatial perception tests or some environment spatial aptitude tasks are used, such as navigation in real and virtual environments. On the other hand, the difference in the magnitude of visualization tests is considered to be almost of null significance; however, the difference increases in favor of men when tasks include the mental rotation component. Unlike men, women show better results on memory and location tests. In turn, Halpern (2000) states that women surpass men when solving tasks of verbal nature, such as verbal fluency, synonym searching, spelling, literature and reading comprehension; and that men surpass women in solving tasks of spatial and mathematical nature, such as mental rotation, spatiotemporal and mechanical problems.

Next, international and national studies are presented that discuss the relationship of age with intellectual abilities, as well as differences between men and women in relation to those abilities. Firstly, the international studies addressing both issues are reported and, subsequently, the national studies, also considering those that investigated the relationship of visuospatial reasoning with age and sex variables, are reported.

Colom (2008), in a study with a Spanish population, states that in the first part of life (until around the age of 18), there is a period of great cognitive development in which an almost linear rise of the intellectual abilities is expected. Once maturity is reached, abilities are consolidated and maintained until approximately 30 to 35 years old and, after this age range, a period of decline is expected. The author reports a study conducted in Spain with the Wechsler Adult Intelligence scale, in which the IQ was noted to remain equal from 16 to 34 years old but, in the period from 35 to 54 years old, the average IQ showed a seven-point reduction; from 55 to 69 years old, 11 points; and, in people over 70 years old, a decline of 22 points was observed in relation to the period of stability.

Berg, Hertzog, and Hunt (1982) have assessed the performance in mental rotation speed and precision activities in subjects over 18 years old. Sixty-six former Washington University students in four distinct age ranges (18-24, 26-35, 44-58 and 60-69) have participated in the study and completed the Primary Mental Abilities Figures Test (PMAF). The results obtained verified that PMAF performance is reduced as age increases, showing spatial information processing deceleration during adulthood. Authors alert, however, that not only the spatial processing is decreased and that it can be a reflection of the generalized reduction experienced by mental process, requiring other studies to assess the mental process and the age range proposed. Authors also studied the sex differences, but the results obtained did not show a significant difference in relation to test performance in both mental rotation speed and precision activities.

In turn, Salthouse (1987) conducted a study to determine whether age differences in image integration or synthesis tasks were related to the reduction in the operation processing ability or if there would be problems in dealing with the amount of information in each operation. The sample included 62 women and 38 young men between 18 and 26 years old, and also adults between 57 and 75 years old, with 63 women and 37 men. The Spatial Memory Task and Mental Synthesis Task tests were performed. The primary results showed that older people were less likely to recognize specific figurative segments, leading to low durability of mental representations and greater slowness to perform image synthesis. Thus, as the required level of abstraction gets more complex, an increased response imprecision is observed in older subjects. In relation to the amount of information to be processed, no significant variation between ages was found. The authors have concluded that aging was associated with the reduction in the operation processing ability, but would not change the amount of information that can be handled in each operation.

Three years later, Salthouse, Babcock, Skovronek, Mitchell, and Paimon (1990) investigated age and experience related effects on spatial ability measures. Fifty architecture students and professionals, Georgia Institute of Technology students already practicing the profession or newly retired subjects were assessed, between 24 and 67 years old. Four tests of the Kit of Cognitive Reference Tests (Ekstrom, French, Harman, \& Dermen, 1976) were used to assess spatial visualization: Form Board Test, Paper Folding Test, Surface Development Test and Cube Comparison Test. The primary results showed that age increase is associated with low levels of performance in different types of spatial visualization tests, regardless of the experience the professional has with the spatial visualization. Thus, the results seem to suggest that experience does not substantially change the spatial visualization performance as age does.

With regard to the sex variable, Pellegrino and Kail (1982) have found differences in performance between men 
and women when applying two tests to evaluate spatial reasoning. The authors stated that this finding can occur due to different strategies of reasoning or specific cognitive processes. When showing the details of the mental processing required by visuospatial tasks is coding stimulus, rotation, comparison and response, it was verified that women require more time for mental rotation than men. However, this finding was considered inconclusive, because it is not known for sure whether the longer time for the rotation performance is due to the women's hesitating attitude to answer or to the need to perform this process several times to build an internal representation of an unfamiliar stimulus, or even to a more cautious attitude of the women in the search for the answer.

Almeida and Campos (1985) investigated the differences between gender and cognition in high-school students from Portugal. The test battery used was Tests of Differential Reasoning, composed of four subtests: abstract, verbal, numerical and spatial reasoning. The results pointed to women's superiority in perceptual acuity and speed tests, and male superiority in the tests that require mental rotation of the stimuli. The authors interpreted this result as an influence of school experiences, of motivational factors and, mainly, of social and cultural stereotype burden associated with the roles of either sex present in the Portuguese culture.

Peters, Chisholm, and Laeng (1995) have tested the spatial ability of 465 students from the University of Guelph School of Engineering, with 55\% male. Firstly, they were submitted to the Mental Rotations Test (MRT) and later to the Paper Folding Test (PFT). The results obtained showed significant differences between sexes in the MRT test, favoring men. Such differences were not observed in the spatial analytical test PFT.

Due to the scarcity of studies with the Asian population and with the aim of checking the pattern of sex differences in spatial reasoning between two nationalities, Geary and DeSoto (2001) conducted a study with 40 Chinese university students from the East China Normal University and with 66 North-American university students from the University of Missouri, all of them between 17 and 42 years old. The objectives included checking the pattern of sex differences in spatial reasoning, using the Card Rotation Test, Cube Comparison Test and Mental Rotation Test. In the Card Rotation Test, no statistically significant sex or nationality differences were identified in the spatial ability. Considering the Cube Comparison Test, in the North-American sample, men showed results significantly higher than women and, in the Chinese sample, women were superior to men, but the result was not statistically significant. In the Mental Rotation Test, the result was significantly higher for males in both samples. Based on these findings, the authors concluded that, in spatial tasks that require rotation of two-dimensional geometric figures, there can be no sex difference depending on the culture or evaluated sample. However, in more complex spatial tasks that require mental rotation of threedimensional figures, there was a clear trend towards male superiority in the results regardless of the culture.
In turn, Tsutsumi, Schröcker, Stachel, and Weiss (2005) conducted a study with students from five classes taking Descriptive Geometry in three Austrian and German universities, Vienna University of Technology (TUW), Vienna University of Applied Arts (UAK) and Dresden University of Technology (TUD), to identify possible sex and experience effects on performance in geometry. Students from the TUW and UAK universities were classified as the ones who had already had experience in fundamental descriptive geometry since the beginning of the course and the ones who had had no experience at all. The Mental Cutting Test (MCT) was used to evaluate students' spatial ability in programs of specific graphic courses. The obtained result confirms the existence of a statistically significant sex difference, with men's result being superior to women's in all groups, except for the UAK experienced group, in which men maintained superiority, but the results were not statistically significant.

Contreras, Rubio, Peña, Colom, and Santacreu (2007) investigated the role of three performance factors in the Spatial Orientation Dynamic Test (SDOT): 'latency response', 'response frequency', and 'invested time', seeking a better understanding of their contribution to the resolution process of spatial tasks and also the existence of possible sex effects. Twothousand, six hundred and twenty four candidates for the air traffic controller training course participated in the study and the results showed that the greater the latency time to respond, the lower the frequency, that is, the lesser the trial and error technique is used to get to an answer and, therefore, the shorter the time invested in the task. According to authors, with regard to the sex difference, men showed a higher latency time to solve the proposed tasks and connect the dots but, once decided, they used fewer clicks to get the answer and obtained the answer in a shorter time. Women used the trial and error technique more, obtaining less latency time, but a greater number of clicks and more time invested in solving the activity.

In Brazil and abroad, there are several studies that have investigated the relationship between visuospatial reasoning and variables such as age and sex. Among them, the study conducted by Baumgartl and Nascimento (2004) has verified the relation between age and performance in the Reasoning Test Battery (Bateria de Provas de Raciocínio - BPR-5). Fiftyseven employees of a company in the State of Minas Gerais participated in the study, with ages ranging from 19 to 45 years old. They were divided into three age groups: 19-27, 28-36 and 37-45, and the results showed statistically significant differences in the Spatial Reasoning (RE-Raciocínio Espacial), Mechanical Reasoning (RM - Raciocínio Mecânico), Numerical Reasoning (RN - Raciocínio Numérico) tests and in the battery Global Performance, showing reduction in the BPR-5 performance with aging. Employees in the first age group showed a significantly higher performance than the ones in the second and third age groups, differentiating them and reinforcing the claim that older people have lower cognitive performance, including the visuospatial reasoning.

The relationship between spatial visualization, spatial reasoning and mechanical reasoning and the variable age were 
also investigated in the study by Silva (2010). Two hundred and thirty-seven high-school students participated, with ages ranging between 15 and 18 years old. The Spatial Visualization Test (TVZ - Teste de Visualização Espacial) and the BPR-5 tests RE and RM were used. Among the results obtained, no statistically significant influence of the variable age was observed for spatial reasoning. There was, however, a statistically significant influence of age on spatial visualization, with the 18-year-old students reaching a higher mean score than the others and differing from the 15-, 16-, and 17-year-old students. Although this result is contradictory to the findings by Berg et al. (1982), Colom (2008) and Woodcock (1999), who state that older people have lower cognitive performance, Silva's sample was restricted to young adults from 15 to 18 years old, who are still in the age of cognitive maturation and, therefore, do not present the performance reduction in those skills.

Regarding the sex variable, some Brazilian studies also verified its relationship with visuospatial reasoning. In this sense, Noronha, Barros, and Nunes (2009) studied the sex differences in relation to intelligence and professional interest constructs. Two hundred and eleven (211) high-school students from the State of Paraná, both male and female, participated in this study, mostly women (58.3\%). Specifically concerning intelligence, the instrument used was the BPR-5, and the results showed a statistically significant sex difference in spatial reasoning $(t=2.96 ; p=.003)$, numerical reasoning $(t=3.68 ; p=.001)$ and in the global score $(t=3.27 ; p=.001)$, in which men obtained higher averages than women.

In turn, Vianna and Wechsler (2010) conducted a study with 60 students, age between 18 and 40 years old, 33 women. All of them were tested using the Woodcock-Johnson III Tests of Cognitive Ability and the results showed that only the average differences in the subtest were statistically significant. Specifically regarding the visuospatial reasoning ability, men reached higher scores and, on the other hand, women reached higher scores on the opposite subtests, such as logical reasoning, processing speed, short-term memory, auditory-visual memory and auditory memory.

Finally, Rueda, and Muniz' (2012) study is highlighted, whose objective was to verify the relationship between the visuospatial reasoning assessed by the Cube Test and the age and sex variables. For that, the responses of 613 university and Air Force Cadet school students from the State of São Paulo were studied and a negative and statistically significant correlation was observed $(r=-.18 ; p<.001)$ between age and the global test result. The authors considered the age ranges from 16 to 19 years old, from 20 to 25 years old and 26 years old or over, and the findings indicated that, as age increases, there is a downward trend in the test results, as the 26-year-old or over group showed the lowest mean (7.32), followed by the 20 to 25 -year group (8.05) and, finally, the 16-to-19-year-old group showed a mean of 9.31 points. This mean difference was statistically significant. Additionally, the same authors compared the performance of men and women in each of the three age groups, as well as in the global sample, and statistically significant differences were verified in all cases, with men showing higher average scores than women. In the study, the authors highlighted the need to carry out investigations with the instrument in other samples, from different states.

Based on that context, the present study aimed at verifying the relationship of the age and sex variables with the visuospatial reasoning ability as assessed by the Cube Test. In addition, a comparative study was carried out between this study sample and the normative test group (Rueda \& Muniz, 2012 ) with respect to the performance results on visuospatial reasoning (Rueda \& Muniz, 2012). Thus, the current study aims to respond to the prior suggestion to conduct studies with the Cube Test in samples from different states, precisely to verify the stability of its results.

\section{Method}

\section{Participants}

Six hundred and eighty-four students from private institutions in Belo Horizonte (Minas Gerais), with three high schools and two higher education institutions. The age ranged from 15 to 57 years old, with a mean of 21 years old $(S D=$ 5.94), both male and female, with 344 (50.3\%) women. The sample was not probabilistic and took into account the ease of contact between researchers and participating institutions.

\section{Instrument}

The Cube Test was used to evaluate visuospatial reasoning (Rueda \& Muniz, 2012). The Cube Test is intended for evaluation of visuospatial reasoning in professional/career guidance processes and also in the evaluation of professionals who need to have this specific reasoning improved in order to have a good performance in their profession. The test consists of 15 tasks and, in each of them, there is a drawing of a 'Rubik Cube' and, right below the drawing, an instruction that suggests one, two or even three distinct rotations. Such rotation(s) may be in the horizontally or vertically position, without movement repetition for a cube in the same line or column.

The Test manual describes a study in which a factor analysis with Promax rotation was conducted to verify the internal structure of the test. The $K M O$ index was .751 and Bartlett's Test of Sphericity measure was $\chi^{2}=1165.77$; $p<.001$, identifying two factors that explained $31.92 \%$ of the variance. Regarding the precision studies, the authors used the Cronbach's alpha coefficient and the Spearman-Brown and Guttman two halves method. Out of the 36 calculated coefficients, 35 were superior to .70 , that is, the Cube Test presented satisfactory accuracy indices.

\section{Procedure}

Data collection. Firstly, an authorization from the principals at the private high schools and from the course coordination at the higher education institutions was requested to conduct the study at the institutions. Only 
subjects were included who signed an informed consent form (ICF) when older than 18, and, in the case of 16- and 17-year old teenagers, those who had the ICF signed by parents or legal guardians and who agreed to participate in the study at the time of test application. Data collection was conducted in group sessions at the premises of each educational institution, with a maximum of 20 people per room. A psychologist with experience in data collection led the test, with the collaboration of a psychology student.

Data analysis. Descriptive statistics were conducted initially to evaluate the participants' performance in the Cube Test. With regard to the relationship with the age variable, a Pearson correlation test was conducted to verify the magnitude and significance of the existing association with visuospatial reasoning. Subsequently, the ages were categorized into age groups, considering those presented by Rueda and Muniz (2012), and the performance of such age ranges in the test was compared using ANOVA variance analysis. As the values obtained showed significant difference, a Tukey test was performed to verify the average score obtained by the age groups and identify which of them could explain this difference. After the age comparison study, Student's t-test was used to verify whether the Cube Test result showed a difference in relation to the sex variable, analyzing the total sample result, as well as each age group separately. Finally, a comparative study was also conducted between the normative average for the Cube Test in the technical manual (Rueda \& Muniz, 2012) and the present study averages, using a One Sample t-test to identify significant differences between the average scores of each study according to sex and age group. It is important to mention that the significance level adopted in all inferential analyses was .05.

\section{Ethical Considerations}

This study received approval from the Research Ethics Committee at the Universidade São Francisco (CAAE: 0158.0.142.000-11).

\section{Results}

In the Cube Test scores, mean values of $7.96(S D=$ 2.91) were found, verifying that a greater number of subjects had scores 7 and 8 , which respectively correspond to $14.2 \%$ and $18.4 \%$ of the sample. The lowest scores corresponded to 1 point $(0.6 \%)$ and 2 points $(1.3 \%)$. These results were expected as they represent the two initial items of the test and, therefore, a low degree of difficulty. Of the total sample, only 11 people (1.6\%) could get all Cube Test items correct.

In an attempt to identify the relationship between age and visuospatial reasoning based on the comparison of age, a Pearson correlation test was conducted between the overall test score and the participants' age, and a negative and statistically significant coefficient was verified $(r=-.23$; $p<.001)$. Although a low magnitude was presented, the result shows that, the greater the age, the lower the score obtained in the Cube Test, that is, younger people tended to score higher than older ones.

Considering that $84.8 \%$ of the sample was in the age range between 16 and 25 years old and that there was a sudden reduction in the number of participants aged over 25 years old, because the sample was similar, it was decided to combine the age groups as the same age groups used in the Cube Test manual study (Rueda \& Muniz, 2012). Thus, the age groups included were up to 19 years old, 20 to 25 years old, and 26 years old or over. Following this categorization, the score of these age groups in the test was compared using ANOVA variance analysis, and the obtained values showed significant difference $[F(2,680)=28.30 ; p<.001]$. Given this result, a Tukey test was performed (see Table 1), to verify the score obtained by the age groups and identify the direction of the possible differences statistically identified between the groups.

Table 1

Subsets Formed by the Tukey Test in Age Groups and Test Scores Ratio

\begin{tabular}{lccc}
\hline \multirow{2}{*}{ Age Groups } & $n$ & \multicolumn{2}{c}{ Alpha Subsets $=.05$} \\
\cline { 3 - 4 } & & 1 & 2 \\
\hline 26 years old or over & 103 & 6.76 & \\
20 to 25 years old & 234 & 7.37 & \\
up to 19 years old & 347 & & 8.73 \\
$p$ & 684 & .088 & 1.00 \\
\hline
\end{tabular}

Among the three age groups formed, only two groups showed a difference in the test scores. The up-to-19-year-old group showed a significantly different performance from the other groups, with a higher mean score. The 20- to 25 -year-old group and the 26-year-old or over group were combined and obtained lower mean scores and, although they did not significantly differ, they followed the criteria as, the higher the age, the lower the average test score.

After the age comparison study in relation to visuospatial reasoning, the study also aimed to verify whether the Cube Test results differed among groups in relation to the sex variable. For that, the Student t-test was used and the results are shown in Table 2.

Table 2

Student t-Test $t$ According to Sex for the Overall Sample in Relation to Age Group

\begin{tabular}{lcccccc}
\hline Age Groups & Sex & $n$ & $M$ & $S D$ & $t$ & $p$ \\
\hline up to 19 years old & Male & 164 & 8.96 & 2.80 & 1.32 & \multirow{2}{*}{.187 } \\
& Female & 183 & 8.54 & 3.11 & & \\
20 to 25 years old & Male & 134 & 7.78 & 2.57 & 2.79 & .006 \\
& Female & 100 & 6.83 & 2.55 & & \\
26 years old or over & Male & 42 & 7.62 & 2.19 & 3.01 & \\
& Female & 61 & 6.13 & 2.63 & & .003 \\
Overall & Male & 340 & 8.33 & 2.71 & 3.29 & \\
& Female & 344 & 7.60 & 3.05 & & .001 \\
\hline
\end{tabular}


Table 2 shows that there was a statistically significant difference between sex in the global sample $(t=3.29 ; p=.001)$, suggesting that men $(M=8.33)$ tend to have higher results in the Cube Test in comparison to women $(M=7.60)$. When the up-to19-year-old group was considered, men and women did not differ significantly $(t=1.32 ; p=.187)$, while the sex difference was significant and favorable to men between 20 and 25 years old $(t=2.79 ; p=.006)$ and 26 years old or over $(t=3.01 ; p=.003)$.

Next, a comparative study was conducted between the manual's normative averages and the present study averages, aiming to identify if there were statistically significant differences between the average sex and age scores. The One-Sample t-test was used and results are shown as follows in Table 3.'

Table 3 shows that men obtained higher averages than women in all age groups and also in the global results in both studies. The global results for men were significantly higher in the manual sample than in the current study $(t=-4.32$; $p<.001)$. In this respect, it is worth mentioning that, in the sample from the Cube Test normative studies, 65 subjects $(10.2 \%)$ were students from the Air Force Cadet School and, therefore, they may have presented higher average results as they are specifically trained with a focus on visuospatial training abilities. Results in males, significantly higher in the normative sample, were the results found in the up-to-19year-old group $(t=-2.89 ; p=.004)$ and in the 20- to 25-year-old group $(t=-5.05 ; p<.001)$, which correspond to the ages of the assessed cadets. In males, the result was not significantly higher only for subjects over the age of $25(t=-1.60 ; p=.116)$. In the female sample, the manual study mean $(M=6.55)$ was significantly higher than in the current study $(M=6.13)$ only in the group aged 26 years or older $(t=-2.44 ; p=.018)$.

\section{Discussion}

This study has been proposed to check the relationship of age and sex variables with the visuospatial reasoning ability as measured by the Cube Test. In addition, a comparative study was undertaken between this study sample and the sample studied by the normative test group (Rueda \& Muniz, 2012) in relation to the results on reasoning visuospatial performance.

In this sense, as regards age, authors like Baumgartl and Nascimento (2004), Colom (2008), Mumaw et al. (1984) and Woodcock (1999) point out that the development of cognitive abilities followed maturity development in human beings, with both happening with aging until the development apex is reached in adulthood and, posteriorly, these abilities undergo a significant decline due aging natural process.

In the current study, the increase in age corresponded to a weak reduction, though significant $(r=-.23 ; p<.001)$, in the visuospatial reasoning score as assessed by the Cube Test. The performance of the up-to-19-year-old group significantly differed from the other age groups, showing a higher score average, and the 20- to 25-year-old group and the 26-year-old or over group were combined, showing lower average scores. This result corroborated the findings by Baumgartl and Nascimento (2004), Colom (2008), Mumaw et al. (1984), Rueda and Muniz (2012), Salthouse

Table 3

t-Test Between the Manual Sample and Current Study Sample Results

\begin{tabular}{|c|c|c|c|c|c|c|c|}
\hline Age Group & Group & Samples & $n$ & $M$ & $S D$ & $t$ & $p$ \\
\hline \multirow{6}{*}{ Up to 19 years old } & \multirow{2}{*}{ Male } & Manual & 102 & 9.59 & 2.70 & \multirow{2}{*}{-2.89} & \multirow{2}{*}{.004} \\
\hline & & Study & 164 & 8.96 & 2.80 & & \\
\hline & \multirow[b]{2}{*}{ Female } & Manual & 79 & 8.48 & 2.71 & \multirow{2}{*}{0.24} & \multirow[b]{2}{*}{.809} \\
\hline & & Study & 183 & 8.54 & 3.11 & & \\
\hline & \multirow{2}{*}{ Overall } & Manual & 181 & 9.11 & 2.75 & \multirow{2}{*}{-2.35} & \multirow{2}{*}{.019} \\
\hline & & Study & 347 & 8.73 & 2.97 & & \\
\hline \multirow{6}{*}{20 to 25 years old } & \multirow{2}{*}{ Male } & Manual & 156 & 8.90 & 2.76 & \multirow{2}{*}{-5.05} & \multirow{2}{*}{$<.001$} \\
\hline & & Study & 134 & 7.78 & 2.57 & & \\
\hline & \multirow{2}{*}{ Female } & Manual & 165 & 7.24 & 2.73 & \multirow{2}{*}{-1.61} & \multirow{2}{*}{.111} \\
\hline & & Study & 100 & 6.83 & 2.55 & & \\
\hline & \multirow{2}{*}{ Overall } & Manual & 321 & 8.05 & 2.86 & \multirow{2}{*}{-3.991} & \multirow{2}{*}{$<.001$} \\
\hline & & Study & 234 & 7.37 & 2.60 & & \\
\hline \multirow{6}{*}{26 years old or over } & \multirow{2}{*}{ Male } & Manual & 61 & 7.89 & 2.54 & \multirow{2}{*}{-1.60} & \multirow{2}{*}{.116} \\
\hline & & Study & 42 & 7.62 & 2.19 & & \\
\hline & \multirow{2}{*}{ Female } & Manual & 44 & 6.55 & 2.16 & \multirow{2}{*}{-2.44} & \multirow{2}{*}{.018} \\
\hline & & Study & 60 & 6.13 & 2.63 & & \\
\hline & \multirow{2}{*}{ Overall } & Manual & 105 & 7.65 & 2.76 & \multirow[b]{2}{*}{-3.58} & \multirow[b]{2}{*}{.001} \\
\hline & & Study & 102 & 6.75 & 2.55 & & \\
\hline \multirow{6}{*}{ Overall } & \multirow{2}{*}{ Male } & Manual & 319 & 8.93 & 2.75 & \multirow{2}{*}{-4.32} & $<001$ \\
\hline & & Study & 340 & 8.33 & 2.71 & & $<.001$ \\
\hline & Female & Manual & 288 & 7.48 & 2.72 & 103 & 306 \\
\hline & remale & Study & 344 & 7.60 & 3.05 & 1.03 & .500 \\
\hline & & Manual & 607 & 8.24 & 2.89 & & \\
\hline & Uverall & Study & 684 & 7.96 & 2.91 & -2.51 & .012 \\
\hline
\end{tabular}


et al. (1990) and Woodcock (1999), as older adult subjects showed a lower performance on the visuospatial tests than the young adults. It is noteworthy, however, that in each study and sample, different cut-off age values were found for the rising, stability and decline phases of visuospatial reasoning. In this sense, an interesting aspect would be to propose more systematic studies to find a more specific moment when the cognitive increase occurs and, mostly, when the cognitive decline starts.

Another aspect that deserves emphasis is the reasons that lead to this decline in the visuospatial reasoning performance. This aspect is intensely investigated, but there is no consensus in science. There have been investigations that have discussed this aspect, which are identified in the current study, such as Pellegrino and Kail (1982), who showed that individual differences in visuospatial ability with advancing age tend to be caused by a decrease in the mental rotation speed or by the difficulty to transform coded information. Salthouse (1987) discuss the low durability of mental representations and greater slowness to perform image synthesis, which would increase the response inaccuracy in the task. Of the referenced studies, the studies conducted by Almeida et al. (2008) and Silva (2010) found no significant differences between the visuospatial reasoning and age, although it is important to mention the low variability of the participants' ages in these investigations.

Although the scientific community has been trying to exhaust the discussions regarding the matter, reaching a consensus about the factors that lead to performance reduction in visuospatial activities is still far from happening. In this sense, the current study has determined the need to establish specific standards, taking into account people's age for the visuospatial reasoning assessment tests. Other studies still need to be carried out though, covering a diversified age group and evaluating specific aspects of visuospatial abilities.

After the age comparison study in relation to visuospatial reasoning, the verification as whether sex would distinguish the subject in this construct was conducted. The results obtained pointed out a statistically significant difference that favored men in the global sample and in most age groups. These data corroborate the findings obtained by Contreras et al. (2007), Geary and DeSoto (2001), Halpern (2000), Peters et al. (1995) and Tsutsumi et al. (2005) in studies conducted abroad; and also reaffirm the findings obtained by Nanda et al. (2009) and Rueda and Muniz (2012) in studies conducted in Brazil. Yet to be highlighted is the fact that, in the up-to-19-year-old group, men and women did not differ significantly in the present study, despite men showing higher averages. Other authors, such as Berg et al. (1982), found no statistically significant differences between spatial reasoning and sex and they disagree on the aforementioned findings.

It is also important to highlight that there are authors, such as Almeida and Campos (1985) and Halpern (2000), who have stressed that reinforcing the difference between genders should be considered less relevant than understanding how this difference has been measured. This is important because intelligence depends on the types of tests the battery contains and what each factor assesses, and it is therefore necessary to conduct studies that further investigate visuospatial reasoning sub-factors and its specificities, as well as the type of task used in the test items, the requirement of knowledge, the response format, among other aspects.

In addition to the studies relating visuospatial reasoning performance with age and sex, a comparative study was conducted, comparing the findings from Rueda and Muniz' (2012) study with the present study findings, aiming to identify whether there were significant differences between the average scores of each study based on sex and age group. The results obtained also showed men with higher averages than women in all age groups and in the overall result of both studies. The overall male result was significantly higher in the manual sample than in the current study sample though. It was verified that $10.2 \%$ of the normative sample was composed of students from the Air Force Cadet School, which might have raised the average result because they have specific training focused on visuospatial abilities. Thus, as demonstrated, it is important to carry out studies that aim at comparing samples and pointing out individual differences between different groups in order to improve psychological tests and to create specific standards for their correction.

\section{Final Considerations}

The study has showed significant differences in visuospatial reasoning in relation to sex and age, suggesting the need to create specific standards for the interpretation of the test results based on these external variables, in order to respect subjects' differences. The comparative study between the current study and the test manual was important to broaden the representativeness of the sample and ratify the need to diversify the normative test samples (Urbina, 2007).

Despite achieving the proposed objective, it is important to consider the study limitations. No random sample was obtained and the selection was based on convenience and easy contact with the institutions, which restricted the age group investigated. The sample was composed of $84.8 \%$ subjects between 16 and 25 years old and above this age range, the number of participants was sharply reduced, limiting the analysis for advanced ages. Also, data collection was conducted only in private institutions in a city in the State of Minas Gerais.

Therefore, it is essential that, in future opportunities, new studies be conducted with samples consisting of subjects of a widely varying age range, mainly including subjects of more advanced ages to better identify visuospatial reasoning rising, stability and decline stages. It would also be interesting to include subjects from other regions in Brazil and with different professional backgrounds to broaden the sample representativeness. 


\section{References}

Adanez, G. P., \& Velasco, A. D. (2002). Construção de um teste de visualização a partir da Psicologia cognitiva. Avaliação Psicológica, 1(1), 39-47.

Almeida, L. S., \& Campos, B. (1985). Raciocínio diferencial de jovens: Experiências escolares e diferenças de sexo. Cadernos de Consulta Psicológica, 1, 41-51.

Almeida, L. S., Guisande, M. A., Primi, R., \& Ferreira, A. (2008). Construto e medida da inteligência: Contributos da abordagem fatorial. In A. Candeias, L. Almeida, A. Roazzi, \& R. Primi (Orgs.), Inteligência: Definição e medida na confluência de múltiplas concepções (pp. 49-79). São Paulo, SP: Casa do Psicólogo.

Baumgartl, V. O., \& Nascimento, E. (2004). A Bateria de Provas de Raciocínio (BPR-5) aplicada a um contexto organizacional. Psico-USF, 9(1), 1-10. doi:10.1590/S1413-82712004000100002

Berg, C., Hertzog, C., \& Hunt, E. (1982). Age differences in the speed of mental rotation. Developmental Psychology, 18(1), 95-107. doi:10.1037/0012-1649.18.1.95

Carroll, J. B. (1993). Human cognitive abilities: A survey of factor analytic studies. Cambridge, United Kingdom: Cambridge University Press.

Colom, R. (2008). Nos limites da inteligência: É o ingrediente do êxito na vida? São Paulo, SP: Vetor.

Contreras, M. J., Rubio, V. J., Peña, D., Colom R., \& Santacreu, J. (2007). Sex differences in dynamic spatial ability: The unsolved question of performance factors. Memory \& Cognition, 35(2), 297-303. doi:10.3758/BF03193450

Ekstrom, R. B., French, J. W., Harman, H. H., \& Dermen, D. (1976). Manual for kit of factor- referenced cognitive tests. Princeton, NJ: Educational Testing Service.

Farah,M.J.(1988). Is visualimagery reallyvisual? Overlooked evidence from neuropsychology. Psychological Review, 95(3), 307-317. doi:10.1037/0033-295X.95.3.307

Geary, D. C., \& DeSoto, M. C. (2001). Sex differences in spatial abilities among adults from the United States and China: Implications for evolutionary theory. Evolution and Cognition, 7(2), 172-177.

Halpern, D. F. (2000). Sex differences in cognitive abilities (3rd ed.). Mahwah, NJ: Lawrence Erlbaum.

Lohman, D. F. (1993, July). Spatial ability and G. Paper presented at the First Spearman Seminar, Plymouth, England. Retrieved from https://www.e-education.psu. edu/drupal6/files/sgam/Spatial_Ability_and_G.pdf

Mumaw, R. J., Pellegrino, J. W., Kail, R. V. Jr., \& Carter, P. (1984). Different slopes for different folks: Process analysis of spatial aptitude. Memory \& Cognition, 12(5), 515-521.

Noronha, A. P. P., Barros, M. V. C., \& Nunes, M. F. O. (2009). Correlações entre interesses profissionais e inteligência em adolescentes. Psicologia: Teoria e Prática, 11(2), 114-128.

Pellegrino, J. W., \& Kail, R. (1982). Process analyses of spatial aptitude. In R. J. Sternberg (Ed.), Advances in the psychology of human intelligence (Vol. 1, pp. 311-365). Hillsdale, NJ: Lawrence Erlbaum.
Peters, M., Chisholm, P., \& Laeng, B. (1995). Spatial ability, student gender and academic performance. Journal of Engineering Education, 84(1), 69-73. doi:10.1002/j.2168-9830.1995.tb00148.x

Prieto, G. (2008). Las aptitudes espaciales. In A. Candeias, L. Almeida, A. Roazzi, \& R. Primi (Orgs.), Inteligência: Definição e medida na confluência de múltiplas concepções (pp. 81-126). São Paulo, SP: Casa do Psicólogo.

Primi, R. (2002). Inteligência fluida: Definição fatorial, cognitiva e neuropsicológica. Paidéia (Ribeirão Preto), 12(23), 57-75. doi:10.1590/S0103-863X2002000200005

Rueda, F. J. M., \& Muniz, M. (2012). Teste dos cubos: Para avaliação do raciocínio visuoespacial. São Paulo, SP: Vetor.

Salthouse, T. A. (1987). Adult age differences in integrative spatial ability. Psychology and Aging, 2(3), 254-260. doi:10.1037/0882-7974.2.3.254

Salthouse, T. A., Babcock, R. L., Skovronek, E., Mitchell, D. R. D., \& Paimon, R. (1990). Age and experience effects in spatial visualization. Developmental Psychology, 26(1), 128-136. doi:10.1037/0012-1649.26.1.128

Silva, D. V. (2010). Habilidades espaciais, raciocínio e desempenho em tecnologias da informação: Estudo correlacional com ensino médio (Unpublished marter's thesis). Universidade São Francisco, Itatiba, SP.

Tsutsumi, E., Schröcker, H.-P., Stachel, H., \& Weiss, G. (2005). Evaluation of students' spatial abilities in Austria and Germany. Journal for Geometry and Graphics, 9(1), 107-117.

Urbina, S. (2007). Fundamentos da testagem psicológica. Porto Alegre, RS: Artmed.

Vianna, C. M. C., \& Wechsler, S. M. (2010, outubro). Avaliação das habilidades cognitivas de adultos pela Bateria Woodcock-Johnson III: Comparação entre gêneros. Anais do Encontro de Iniciação Científica, 15. Retrieved from http://www.puc-campinas. edu.br/websist/portal/pesquisa/ic/pic2010/res umos/2010924_193429_502028297_resaro.pdf

Woodcock, R. W. (1999). What can Rasch-based scores convey about a person's test performance? In S. E. Embretson, \& S. L. Hershberger (Eds.), The new rules of measurement: What every psychologist and educator should know (pp. 105-127). Mahwah, NJ: Lawrence Erlbaum.

Juliana Carnevalli Siqueira Nery holds a master's degree in Psychology from Universidade São Francisco.

Fabián Javier Marín Rueda is a Professor at the Universidade São Francisco.

Received: Oct. 24, 2012

1st Revision: Oct. 24, 2013

2nd Revision: Jan. 20, 2014

Approved: Mar. 6, 2014

How to cite this article:

Nery, J. C. S., \& Rueda, F. J. M. (2014). Visuospatial reasoning and its relation to external variables. Paidéia (Ribeirão Preto), 24(58), 197-204. doi: 10.1590/1982-43272458201407 